\title{
IoT Based: Smart Traffic Light Controller
}

\author{
Faisal Al Kalbani \\ Nada Al Bulushi \\ Syed Imran
}

\author{
MIDDLE EAST COLLEGE \\ Middle East College \\ Middle East College
}

In this paper an improved smart light controller is created. The system is based on Internet of Things. The system is created by IoT components like Arduino UNO, RFID and IR sensors. The traffic density is measured by IR sensors. RFID technology is used for ambulance vehicles to give a green path. The system works automatically and interrupted only when an emergency vehicle sends an order to get a green path.

\section{Introduction}

Muscat city is the fastest growing city in Oman. As a result, number of cars are increasing considerably. Technology has some solutions to overcome the traffic congestion. Smart cities are one idea to implement in such a city like Muscat.

Smart Traffic Light Controller is not a new system, but it needs a lot of improvements. This system adds a database of the traffic congestion and gives a real time feedbacks about congestions in junctions.

This system is part from smart city. It focuses on controlling the traffic lights by using IoT devices. The system detects how long is the congestion in one direction and will give the traffic light a suitable time to let all vehicles passing the junction smoothly. The system gives the priority for passing for emergency vehicles.

\section{Literature Review}

Internet of Things has developed primary by the large corporations. Especially, in the field of commodity chains. The need of tracking objects to gain more speed and reduce error. Day by day, other technologies helped internet of things to be more efficient and represents the future of communication. These technologies are wireless sensors and microprocessors board. IoT helps companies and organizations to monitor and control objects through an automated system.

IoT Stands of two basic words "Internet" and "Things". Internet is the global network that let many users in different networks (private or public) to communicate using (TCP/IP) protocol. As the study around the more than 2 billion users are involved in this worldwide network. The second word is "things" which indicates any object or person can be identified in the real world. That thing also could be an animal or a non-living thing. Many definitions are available for Internet of Things.

This research article gives an overview of Internet of Things and its usage in our daily life. In Addition, the authors explained IoT architecture and its technologies. Starts from the beginning of Internet of Things which is the name. Then goes to talk about the future of internet of things and how it is related to other technologies which are led IoT to be more advanced and useful. At the end, the author talked about the future and how the current world will transform to an intelligent world by transforming objects to IoT objects.

Arduino board is a standard SBC (Single Board Computer). It gives the ability to build an intelligent network. That intelligent network can monitor, control and access internet using sensors. Arduino 
board are very popular in the field of Internet of things because of reliability, connectivity and budget value. Arduino board works as a small computer. It provides many different functions depends on the programming and external unites connected to Arduino board.

\begin{tabular}{|l|l|l|l|}
\hline Feature & Arduino UNO & Arduino Due & Arduino Galileo \\
\hline Processor & AT Mega & AT91S & Intel Quark \\
\hline Speed & $16 \mathrm{MHz}$ & $84 \mathrm{MHz}$ & $400 \mathrm{MHz}$ \\
\hline External memory (SD-Card) & On shield only & On shield only & $32 \mathrm{MB}$ \\
\hline Ethernet & On shield & On shield & $100 \mathrm{Mb} / \mathrm{s}$ \\
\hline Flash memory & $32 \mathrm{~KB}$ & $512 \mathrm{~KB}$ & $8 \mathrm{MB}$ \\
\hline
\end{tabular}

Table 1.

Arduino boards' family are Arduino UNO, Arduino Due and Arduino Galileo. Arduino boards like other single boards computer have some limitations, such as low memory and low speed. Arduino board can be extended in functionalities by using another element called "shields".

\section{Previous Studies}

\section{a. Design and Implementation Smart Traffic Light Using GSM and IR}

This is a summary of the above article done by Kareem; Jabbar. In the article, Authors begin by talking about traffic congestion increasing. The main objective is reducing the waiting time in emergency situations. Two parts are used, software part and hardware part. The software part gets signals from the other part to control traffic lights by using two methods. The first one is by calling the system to turn the traffic light to green in the required lane. The second one is by using IR sensors to detect the specific vehicle (like ambulance vehicle).

Advantages: Open lane for specific vehicles in emergency cases. Two ways of controlling the system (GSM and IR sensors).

Disadvantages: Calling the system using GSM technology may fail regarding to no balance or weak coverage area. Using IR sensors to detect a specific car before reaches the junction is very difficult to implement and may cause some malfunctions in the system. In closing, the aim of the project is to reduce the crowding in the emergency situations.

\section{b. Ambulance with Automatic Traffic Light Control}

The paper focuses on emergency conditions to save human's life. Reaching the hospital without delay caused by the ambulance at the road intersections. The aim is to let the ambulance arrives hospital as fast as possible. The system consists of two parts. The first one is related to patient's status. Basic information about the patient are send to the hospital for the treatment. The second part is related to traffic light. Ambulance driver clear the path by controlling traffic light.

My project involved mainly in Arduino boards. This research paper is focusing in Arduino as a popular SBC around the world. Authors explained about its family, architecture and shields used on it. Also, an explanation of how to configure An Arduino board using IDE. It will be very useful for my project.

The authors use IoT within the existing internet infrastructure to save patient's life while using ambulance vehicle. The project controls the traffic signals at the needed time. Arduino Uno board, Arduino Ethernet shield board, different sensors are used as hardware components. Arduino Software, Arduino Environment and Cayenne app are used as software components. 


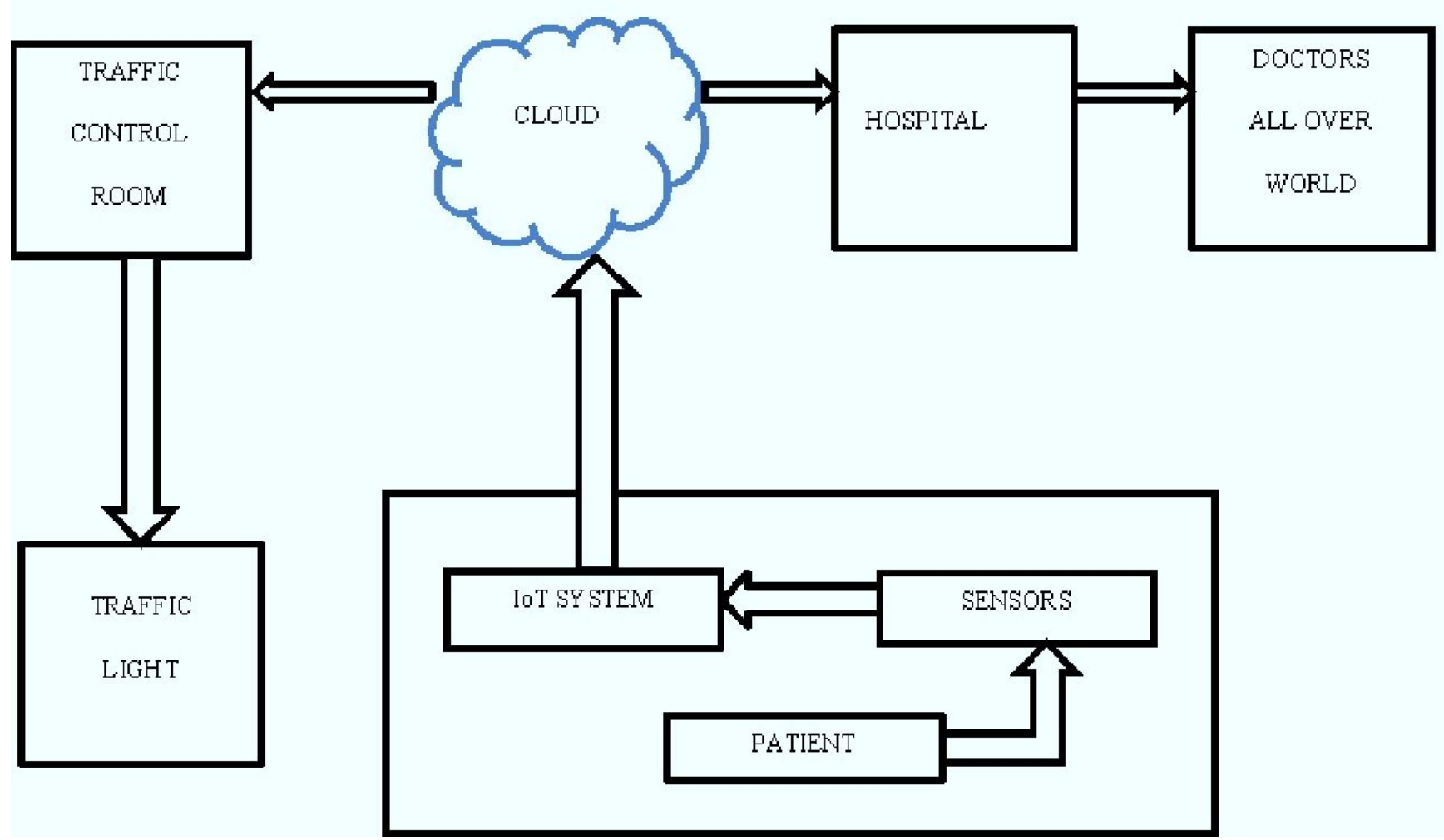

Figure 1. High-level architecture of system

\section{INNOVATIVE TECHNOLOGY FOR SMART ROADS BY USING IOT DEVICES}

The project is mainly about traffic congestion as a worldwide problem. The project is for India as it is the second most populous country. The traffic lights there are based on fixed time concept. Trying to apply smart devices on the road with a low-cost innovative technology to solve the problem. The used devices are ultrasonic sensors, light sensors motion sensors camera and IoT devices. The devices use the exciting network infrastructure.

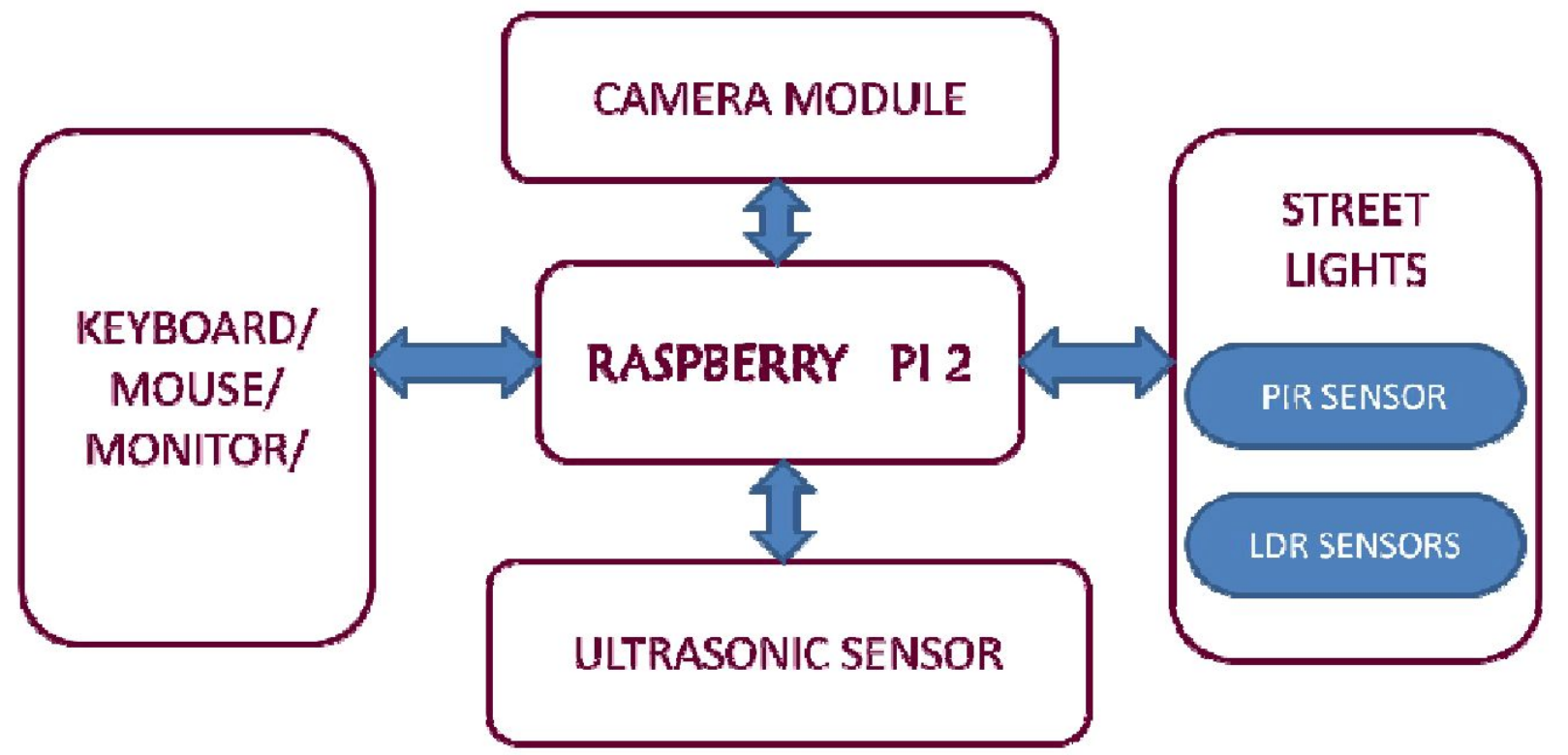




\section{Journal of Student Research}

Figure 2. Block Diagram for Smart Roads using Raspberry Pi 2

The system uses cameras for detecting traffic congestion and controlling signals. There is one camera for each direction fixed alongside the traffic light. The camera takes sequence of images and analyze the image to calculate the number of vehicles and control the traffic light.

\section{Problem Definition}

In Muscat city, traffic lights operate in a systematic way which cause a lot of delay for drivers in some cases. It gives every direction a specific time without reading the current traffic jam for each lane. Traffic flow needs to be more smoothly. Connecting traffic light with a smart system to control the timing is the aim.

Muscat Municipality doesn't have records about how much is the jam in road junction. So, it will be difficult to recognize which junction needs to be replaced with a bridge. Quality of road can be improved by using smart systems.

\section{Hardware implementation}

\section{a. Arduino UNO}

An open-source platform for Arduino boards. It is a user-friendly software. It enables the user to enter instructions for the board.

\section{b. IR sensors}

An open-source platform for Arduino boards. It is a user-friendly software. It enables the user to enter instructions for the board.

\section{SOFTWARE AND ENVIRONMENT}

\section{a. Arduino IDE}

An open-source platform for Arduino boards. It is a user-friendly software. It enables the user to enter instructions for the board.

\section{Framework Diagram}

Figure 3. Framework Diagram

- Sensors: Collect data from each lane in the traffic junction and send it to the microcontroller.

- Device: It contains the program and configuration required to control the sensors. Also, it receives the collected date from the sensors to the cloud platform.

- Service: ThingSpeak platform is used in this project as a cloud service for IoT devices. Also, it provides a security for end-to-end data.

- Interface: An application cloud-based and local program to serves the end-user of the system. 


\section{Logical Design}

Figure 4. Logical Design

\section{Physical Design}

Figure 5. Physical Network Design

\section{a. Private Cloud}

\section{Figure 6.}

In private cloud the infrastructure of the network is related to a single organization and implemented in internally not over a third-party cloud. The above system includes some main parts like the sensors, connectivity and the user interface. The first device is the IR sensor which reads the density of cars in a lane then send it to the Arduino UNO. Then microcontroller sends the date to the private cloud.

Behind the fire wall is the private cloud where all the data collected by sensors are stored and managed by datacenter. All servers, cables and software are managed securely. The final step is the user interface which is related to the application or website. It may be called as system dashboard. All data and the state of the system can be monitored form it.

\section{b. Public Cloud}

Figure 7.

In public cloud the system is simpler than what it is in private cloud. Simply it starts from the sensors to the Arduino UNO and send it to the public cloud. The deference is in public cloud many services are available to choose from. In this system, ThingsSpeak is selected. ThingsSpeak uses API to send the data to a user interface. The data can be sent by using HTTP over internet of over LAN.

\section{Network Design}

Figure 8. Network Design

\section{Experimental Result}

\section{Figure 9.}

The above figure shows the main components required to accomplish the connection. The components are Arduino UNO, IR sensors, LED lights (RED, Green and Yellow), resistors, jumpers 
and breadboard. There are four lanes, so 12 LEDs should be used. Those LEDs connected to the resistors to limit the current and protect them from burning.

\section{Acknowledgements}

The writer desires to express his most sincere appreciation and thanks to everyone who helps me for his encouragement and advice through the course of this study and for his help to accomplish the system.

Thanks go to the faculty members of Department of Computing and to the Head, Faculty of Computing for supplying the source of information for this work.

Thanks, are also due to Supervisor for successfully guiding the project work towards its completion. I would like to apologize to all other people who helped me to accomplish this project I missed to name them here.

\section{References}

Jetronic, V. \& Matijevic, M., 2016. Overview of Architectures with Arduino Boards as Building Blocks for Data Acquisition and Control Systems. iJOE, 12(7), pp. 10-17.

Guru99 , 2019. What is Spiral Model? When to Use? Advantages \& Disadvantages. [Online] Available at: https://www.guru99.com/what-is-spiral-model-when-to-use-advantagesdisadvantages.html [Accessed 2605 2019].

Haire, L., 2019. Acceptance Planning in Project Management. [Online] Available at: https://study.com/academy/lesson/acceptance-planning-in-project-management.html [Accessed 28 05 2019].

Hordos, L., 2019. Weaknesses of Brainstorming. [Online] Available at: https://bizfluent.com/info-8156056-weaknesses-brainstorming.html [Accessed 2705 2019].

Inc., S., 2019. WHAT IS A RESOURCE PLAN. [Online] Available at:

https://www.smartsheet.com/resource-planning-templates [Accessed 0106 2019].

Jha, G., 2017. 4 Data Collection Techniques: Which One's Right for You?. [Online] Available at: https://blog.socialcops.com/academy/resources/4-data-collection-techniques-ones-right/ [Accessed 0106 2019].

Madakam, S., Ramaswamy, R. \& Tripathi, S., 2015. Internet of Things (IoT): A Literature. Journal of Computer and Communications, Volume 3, pp. 164-173.

Morse, A. P., 2016. Waterfall Model: What Is It and When Should You Use It?. [Online] Available at: https://airbrake.io/blog/sdlc/waterfall-model [Accessed 2605 2019].

project-management.com, 2018. Types of Risk in Project Management. [Online] Available at: https://project-management.com/types-of-risk-in-project-management/ [Accessed 2205 2019].

rayo, 1., 2015. Modified Waterfall Model. [Online] Available at:

https://prezi.com/ne8i4-bsjeyf/modified-waterfall-model/ [Accessed 2705 2019].

Ray, S., 2017. The Risk Management Process in Project Management. [Online] Available at: https://www.projectmanager.com/blog/risk-management-process-steps [Accessed 2305 2019]. 


\section{Journal of Student Research}

Reints, W., 2017. 100 years of Traffic Light. [Online] Available at:

https://www.siemens.com/press/en/feature/2014/infrastructure-cities/2014-08-trafficlights100.php [Accessed 2804 2019].

Rouse, M., 2005. Prototyping Model. [Online] Available at: https://searchcio.techtarget.com/definition/Prototyping-Model [Accessed 2505 2019].

S.N.Sivaraj, K.Vigneshwaran, S.Vigneshwaran \& Priyan, M., 2017. Iot Ambulance With Automatic Traffic Light Control. SSRG International Journal of Industrial Engineering, Issue special issue, pp. 12-18.

S, S. et al., 2016. Innovative Technology for Smart Roads by Using IOT Devices. International Journal of Innovative Research in Science,, 5(10), pp. 190-194.

Thaar, K. \& Mays, J., 2018. DESIGN AND IMPLEMENTATION SMART TRAFFIC LIGHT USING GSM AND IR.. Iraqi Journal for Computers \& Informatics Ijci, 44(2), pp. 1-5.

The Interaction Design Foundation, 2019. What is Brainstorming?. [Online] Available at: https://www.interaction-design.org/literature/topics/brainstorming [Accessed 2405 2019].

tricider, 2019. Benefits of brainstorming. [Online] Available at: https://www.tricider.com/Benefits-ofBrainstorming [Accessed 2505 2019].

tutorialspoin, 2019. V-Model. [Online] Available at:

https://www.tutorialspoint.com/sdlc/sdlc_v_model.htm [Accessed 2605 2019].

Walden, D. D. et al., 2010. Risk Mitigation Planning, Implementation, and Progress Monitoring. In: 3.2, ed. INCOSE Systems Engineering Handbook. s.l.:International Council on Systems Engineering, pp. 213-225. 